\title{
PENGEMBANGAN MEDIA PEMBELAJARAN ELECTRONIC BOOK (E-BOOK) INTERAKTIF MULTIMEDIA DALAM MATA PELAJARAN TEKNIK ANIMASI 3D DAN TEKNIK ANIMASI 2D DI JURUSAN MULTIMEDIA SMK NEGERI 3 SINGARAJA
}

\author{
I W. A. Ambhara Sanuaka1', K. Udy Ariawan², I Wayan Sutaya ${ }^{3}$ \\ ${ }^{1}$ Prodi Pendidikan Teknik Elektro,Universitas Pendidikan Ganesha, Singaraja \\ ${ }^{2,3}$ Prodi Teknik Elektronika, Universitas Pendidikan Ganesha, Singaraja \\ e-mail: sanuigung@gmail.com , udyariawan@gmail.com, sutaya.elkt@gmail.com
}

\begin{abstract}
Abstrak
BSE atau Buku Sekolah Elektronik merupakan buku digital yang digunakan di berbagai sekolah. Namun terdapat kelemahan dari buku sekolah elektronik ini yaitu belum adanya konten video yang disisipi, baik video tutorial maupun video ilustrasi serta tampilan dari buku sekolah elektronik ini masih menggunakan efek scroll. Sehingga perlu adanya video untuk merangsang siswa dalam belajar serta memberikan efek berupa flip untuk menarik tampilan dari buku digital atau sering disebut E-Book. Tujuan penelitian ini untuk menghasilkan media pembelajaran electronic book (e-book) interaktif multimedia dalam mata pelajaran Teknik Animasi 3D dan Teknik Animasi 2D di Jurusan Multimedia SMK Negeri 3 Singaraja. Penelitian ini dilakukan dengan menggunakan metode Research and Development dalam bidang pendidikan. E-book yang dikembangkan sesuai dengan mata pelajaran yang berada di Jurusan Multimedia yaitu Animasi 2 Dimensi dan Animasi 3 Dimensi. Tampilan e-book didesain tampak nyata atau 3D dengan menambahkan efek flip serta di dalam materi e-book disisipi konten multimedia berupa gambar dan video baik video tutorial maupun video ilustrasi sebagai pendukung interaktifnya e-book yang dikembangkan. Dengan menggunakan beberapa bantuan software, hasil yang diperoleh dari mengembangkan e-book interaktif multimedia terdapat perubahan penyajian dalam bentuk flip. Secara materi dilakukan dengan pendekatan nyata dalam bentuk video, baik video tutorial maupun video ilustrasi. Hasil uji validasi dari validator dengan menggunakan angket menyatakan media pembelajaran e-book interaktif multimedia dalam mata pelajaran Teknik Animasi 3D dan Teknik Animasi 2D sesuai dengan konsep pada materi yang terdapat dimasing-masing mata pelajaran.
\end{abstract}

Kata Kunci: e-book, multimedia, flip, animasi 2D, animasi 3D

\begin{abstract}
BSE or Electronic School Book is a digital book that are used in many schools. But there are weeknesses of this electronic school book is not insert video content, either video of tutorials or video of illustrations and display of electronic school books still use the scroll effect. So it needs a video to stimulate the students to learn and give a flip effect to attract display of digital books or often called the E- Book. The purpose of this research to produce interactive multimedia electronic book (e-book) of learning media in the subjects of 3D Animation Techniques and 2D Animation Techniques at the Department of Multimedia SMK Negeri 3 Singaraja. This research has been done by using the research and development method in education field. E-book is developed based on subject that already exist in Multimedia majority, such as 2 Dimension Animation and 3 Dimension Animation. The display of e-book itself is designed like a real content or $3 D$ with adding flip effect and inside of the material which is being developed, it has several multimedia contents such as picture, animation and video that can support the developing of interactive $e$ book. By using various software support, the results obtained from developing interactive multimedia ebook, there are changes in presentation in the form of a flip. The material is done with a real approach in the form of video, such as video of tutorials or video of illustrations. The results of the validation test of the validator using a questionnaire stating interactive multimedia electronic book (e-book) of learning media in the subject 3D Animation Techniques and 2D Animation Techniques in accordance with the concept of the material contained in the respective subjects.
\end{abstract}

Keywords: ebook, multimedia, flip, 2D animation, 3D animation 


\section{Pendahuluan}

Pendidikan salah satu komponen terpenting dalam kehidupan ini. Maju atau tidaknya sumber daya manusia ditentukan oleh pendidikan yang diterimanya. Secara etimologi pendidikan atau dikenal dengan paedagogie berasal dari bahasa Yunani, terdiri dari kata "PAIS", artinya anak, dan "AGAIN" diterjemahkan membimbing, jadi paedagogie yaitu bimbingan yang diberikan kepada anak (Ahmadi, dkk, 2001:69). Menurut Ki Hajar Dewantara (dalam Ahmadi, dkk, 2001:69), mendidik adalah menuntun segala kekuatan kodrat yang ada pada anak-anak agar mereka sebagai manusia dan asebagai anggota masyarakat dapat mencapai keselamatan dan kebahagiaan yang setinggi-tingginya. Pendidikan dapat diperoleh dimana saja, kapan saja dan untuk siapa saja baik formal maupun non formal.

Menurut Degeng (dalam Asyhar, 2012:7) menyatakan bahwa pembelajaran pada dasarnya merupakan upaya membelajarkan pembelajar (anak, siswa, peserta didik). Pembelajaran merupakan suatu kegiatan yang melibatkan seseorang dalam upaya memperoleh pengetahuan, keterampilan, dan nilai-nilai positif dengan memanfaatkan berbagai sumber untuk belajar. Pembelajaran (Asyhar, 2012:7) adalah segala sesuatu yang dapat membawa informasi dan pengetahuan dalam interaksi yang berlangsung antara pendidik dengan peserta didik.

Secara etimologi, media berasal dari Bahasa Latin, merupakan bentuk jamak dari kata "medium" yang berarti "tengah, perantara, atau pengantar" (Asyhar,2012:4). Media memiliki peran yang sangat penting, yaitu suatu sarana atau perangkat yang berfungsi sebagai perantara atau saluran dalam suatu proses komunikasi antara komunikator dengan komunikan (Asyhar, 2012:5). Dengan adanya media pembelajaran ini guru atau pengajar dapat memaparkan materi dengan mudah serta dapat menstimulasi pemikiran peserta didik sehingga materi yang diterima peserta didik mudah dimengerti.

Media pembelajaran dapat dikatakan sebagai semua alat yang dapat digunakan sebagai media dalam pembelajaran. Media pembelajaran menurut Gerlach dan Ely (dalam Asyhar, 2012:7), memiliki cakupan yang sangat luas, yaitu termasuk manusia, materi, atau kajian yang membangun suatu kondisi yang membuat peserta didik mampu memperoleh pengetahuan, keterampilan, atau sikap.

Sesuai dengan karakteristik media pembelajaran dibagi menjadi empat jenis, yaitu media audio, media visual, media audio visual, dan multimedia. Semua jenis media, dari media audio, media visual, maupun media audio visual kini dapat digunakan dalam satu media yakni multimedia. Multimedia merupakan penggabungan dari dua kata yaitu "multi" dan "media". Multi berarti banyak sedangkan media merupakan bentuk jamak dari medium yang berarti perantara. Istilah multimedia digunakan untuk menyatukaan teknologi digital dan analog di bidang entertainment, publishing, communication, marketing, advertising, dan juga commercial (Asyhar, 2012:75).

E-book atau disebut dengan buku digital, berawal dari sebuah buku ajar yang dikembangkan. Menurut Priyanto (dalam Perdana, 2013) buku ajar dapat mendukung terwujudnya program student centered learning (SCL), dimana paradigma belajar di sekolah diarahkan lebih banyak pada siswa sebagai subyek pembelajaran dan guru hanya bertindak sebagai fasilitator. Salah satu buku ajar adalah buku sekolah elektronik (BSE). Namun, dalam penggunaannya di berbagai sekolah memiliki kelemahan yang patut disempurnakan dengan menampilkan simulasi dengan memadukan video, audio, dan gambar yang dikemas ke dalam ebook. Keuntungan e-book dapat digunakan dimana saja, kapan saja dan digunakan oleh siapa saja. Pembaca dapat mengakses e-book secara online maupun offline.

Arsyad (2008) berpendapat bahwa konsep interaktif paling erat kaitannya dengan media berbasis komputer, interaksi dalam lingkungan pembelajaran berbasis komputer umumnya mengikuti tiga unsur yaitu: 1) urut-urutan instruksional yang dapat diurutkan, 2) jawaban/respon atau pekerjaan siswa dan 3) umpan balik yang dapat disesuaikan. Media interaktif biasanya mengacu pada produk dan layanan pada sistem berbasis komputer digital yang merespontindakan pengguna dengan menyajikan konten seperti teks, grafik, animasi, video, audio, dan lain-lain. 
Desain tampilan buku digital yang kini banyak diminati adalah ebook tiga dimensi yang dikenal dengan flipbook, dimana halaman sudah bisa dibuka seperti membaca buku di layar monitor (Riyanto et al., dalam Perdana, 2013). Flip book maker merupakan salah satu software yang dapat digunakan untuk menyajikan referensi atau buku dalam tampilan elektronik. Flip book maker adalah sebuah software yang mempunyai fungsi untuk membuka setiap halaman menjadi layaknya sebuah buku. Dengan menggunakan perangkat lunak tersebut, tampilan media akan lebih variatif, tidak hanya teks, gambar, video, dan audio juga bisa disisipkan dalam media ini sehingga proses pembelajaran akan lebih menarik (Ramdania dalam Sugianto,dkk, 2013).

Kata animasi itu sendiri sebenarnya penyesuaian dari kata animation yang berasal dari kata dasar to animate dalam kamus umum Inggris - Indonesia berarti menghidupkan (Wojowasito, 1997). Secara umum animasi adalah suatu kegiatan menghidupkan, menggerakkan benda mati; Suatu benda mati diberikan dorongan kekuatan, semangat dan emosi untuk menjadi hidup dan bergerak atau hanya berkesan hidup baik dalam 2 dimensi maupun 3 dimensi.

Jurusan Multimedia di SMK Negeri 3 Singaraja memiliki kurang lebih sepuluh mata pelajaran yang diajarkan. Pada mata pelajaran Teknik Animasi 2 Dimensi serta Teknik Animasi 3 Dimensi memiliki tingkatan materi berjenjang, sehingga untuk mendalami serta menguasai mata pelajaran ini tidak singkat. Terlebih lagi materi yang diberikan hanya berlangsung ketika jam belajar mengajar berlangsung serta materi yang disajikan belum didukung dengan video tutorial, sehingga peserta didik kurang mampu mengasah pengetahuan dan pemahaman mengenai mata pelajaran Teknik Animasi 3 Dimensi dan Teknik anikasi 2 dimensi diluar proses kegiatan belajar mengajar.

Berdasarkan uraian diatas, maka perlu dikembangkan sebuah media pembelajaran interaktif sebagai pengembangan dari buku sekolah elektronik dalam mata pelajaran Teknik Animasi 3D dan Teknik Animasi 2D. Oleh sebab itu, peneliti akan mengembangkan media pembelajaran berupa e-book interaktif dengan memberikan efek flip pada tampilannya serta menyisipkan konten multimedia berupa video baik video tutorial maupun video ilustrasi didalamnya yang dapat digunakan sebagai inovasi dalam proses kegiatan belajar mengajar pada mata pelajaran pada Jurusan Multimedia khususnya pada mata pelajaran Teknik Animasi 3D dan Teknik Animasi 2D di SMK Negeri 3 Singaraja.

Masalah dalam penelitian ini adalah bagaimana mengembangkan media pembelajaran electronic book (e-book) interaktif multimedia dalam mata pelajaran teknik animasi 3D dan teknik animasi 2D di Jurusan Multimedia SMK Negeri 3 Singaraja dengan memberikan efek flip serta menyisipkan video baik video tutorial maupun video ilustrasi?

Penelitian ini bertujuan untuk menghasilkan media pembelajaran electronic book (e-book) interaktif multimedia dalam mata pelajaran teknik animasi 3D dan teknik animasi 2D di Jurusan Multimedia SMK Negeri 3 Singaraja yang layak ditinjau dari segi materi, media, design, serta bahasa dan dapat digunakan sebagai referensi serta media pembelajaran; Untuk mengetahui respon siswa (peserta didik) terhadap media pembelajaran electronic book (e-book) interaktif multimedia dalam mata pelajaran teknik animasi 3D dan teknik animasi 2D di Jurusan Multimedia SMK Negeri 3 Singaraja.

Manfaat yang didapatkan dari penelitian ini adalah

1. memberikan sumbangan pemikiran berupa pengembangan media pembelajaran dalam rangka meningkatkan kualitas pendidikan

2. siswa dapat menggunakan media pembelajaran dimana saja, kapan saja sehingga dapat menumbuhkembangkan kemampuan siswa dalam mata pelajaran jurusan multimedia khususnya mata pelajaran teknik animasi 3d dan teknik animasi $2 \mathrm{~d}$

3. mempermudah peserta didik untuk belajar dan menambah wawasan serta ilmu pengetahuan.

4. sebagai referensi bagi pendidik dan peserta didik dalam mata pelajaran jurusan multimedia khususnya mata pelajaran teknik animasi 3d dan teknik animasi $2 d$

5. menambah wawasan, pengetahuan, serta keterampilan peneliti dalam pengembangan media pembelajaran. 
Batasan masalah pada penelitian ini mencangkup :

1. mata pelajaran yang dijadikan e-book sebanyak dua mata pelajaran yakni teknik animasi 3 dimensi, dan teknik animasi 2 dimensi.

2. sampel yang akan diteliti terletak di smk negeri 3 singaraja pada kelas xi jurusan multimedia.

3. pengaksean e-book berupa masih menggunakan localhost.

\section{Metode}

Penelitian ini dilakukan dengan menggunakan metode Penelitian dan Pengembangan (Research and Development) dalam bidang pendidikan. Langkah-langkah dalam metode penelitian dan pengembangan menurut Sugiyono (2015:409-426) adalah (1) potensi dan masalah, (2) pengumpulan data, (3) desain produk, (4) validasi desain, (5) revisi desain, (6) ujicoba produk, (7) revisi produk, (8) ujicoba pemakaian, (9) revisi produk, dan (10) produksi masal. Namun pada penelitian ini hingga langkah ke lima.

Metode penelitian pada tahap I ini dilakukan untuk memvalidasikan hasil produk dengan ahli media dan isi pada media pembelajaran electronic book (e-book) interaktif multimedia dalam mata pelajaran teknik animasi 3D dan teknik animasi 2D di Jurusan Multimedia SMK Negeri 3 Singaraja.

Subjek dalam penelitian pada tahap I ini adalah media pembelajaran dalam bentuk perangkat lunak berupa e-book interaktif multimedia dengan menggunakan localhost yang kelak akan digunakan sebagai referensi atau media pembelajaran oleh guru dan siswa Jurusan Multimedia di SMK Negeri 3 Singaraja.

Teknik pengumpulan data pada tahap I ini berupa penyebaran kuisioner atau angket yang disusun dengan memperhatikan delapan prinsip penulisan menurut Uma Sekaran (dalam

Sugiyono, 2015:200-202). Teknik ini digunakan untuk memperoleh data mengenai perbaikan atau revisi serta masukan dari ahli media dan materi sebelum melanjutkan ke tahap berikutnya.

Untuk mengetahui kelayakan e-book interaktif multimedia yang telah dibuat untuk referensi atau media pembelajaran, maka digunakan instrumen berupa angket yang diberikan kepada ahli media dan ahli materi.

Validasi E-book interaktif dilakukan oleh validator materi dan validator media pembelajaran yang dianalisis menggunakan teknik deskriptif presentase dengan rumus. (Sudijono dalam Perdana, 2013:25):

$$
P=\frac{f}{N} \times 100 \%
$$

Keterangan:

$\mathrm{P}=$ presentase skor

$f=$ jumlah skor yang diperoleh

$\mathrm{N}=$ jumlah skor maksimum

Validator materi dan media akan menjawab pertanyaan dengan memberi skor sesuai rubrik validasi (skor tertinggi=1 dan skor terendah=0). Hal ini bertujuan untuk mendapatkan jawaban yang tegas terhadap suatu permasalahan yang ditanyakan. (Sugiyono, 2015).

Penentuan kriteria validitas ditentukan dengan cara sebagai berikut :

a. Menentukan persentase skor ideal (skor maksimum), yaitu $(1: 1) \times 100 \%=100 \%$

b. Menentukan persentase skor terendah (skor minimum), yaitu $(0: 1) \times 100 \%=0 \%$

c. Menentukan range, yaitu $100 \%-0 \%=100 \%$

d. Menetapkan kelas interval, yaitu $=2$ (setuju, tidak tidak setuju)

e. Menentukan panjang interval, yaitu 100:2 = 50\%

Berdasarkan perhitungan di atas, maka rentang persentase dan kriteria kualitatif uji kelayakan media dapat ditetapkan pada Tabel 1 
Tabel 1. Rentang persentase dan kriteria kualitatif uji kelayakan media

\begin{tabular}{cc}
\hline $\begin{array}{c}\text { Rentang persentase } \\
(\%)\end{array}$ & Kriteria kualitatif \\
\hline $50 \%-100 \%$ & Layak \\
$0 \%-49 \%$ & Tidak Layak \\
\hline
\end{tabular}

Perancangan desain produk terdiri dari empat bagian, yaitu: (1) Perencanaan Pengumpulan Data; (2) Analisis Kebutuhan; (3) Desain; dan (4) Perancangan Produk. Perancangan e-book interaktif multimedia berdasarkan kompetensi dasar yang terdapat pada setiap mata pelajaran terdapat pada Jurusan Multimedia. Namun mata pelajaran yang diambil adalah mata pelajaran animasi 2 dimensi dan animasi 3 dimensi.

Kebutuhan yang diperlukan dalam perancangan produk ini terdiri dari dua buah e-book yaitu mata pelajaran animasi 2 dimensi dengan $13 \mathrm{bab}$, dan animasi 3 dimensi dengan 9 bab. Pada setiap materi yang membahas mengenai tutorial, dan hal yang mendukung didalamnya terdapat gambar dan video didalam produk yang dihasilkan.

Perencanaan desain produk merupakan gambaran awal dari e-book interaktif multimedia yang akan dibuat. E-book interaktif multimedia merupakan buku digital yang digunakan sebagai referensi baik oleh guru maupun oleh siswa. Berikut ini desain dari tampilan awal e-book interaktif multimedia

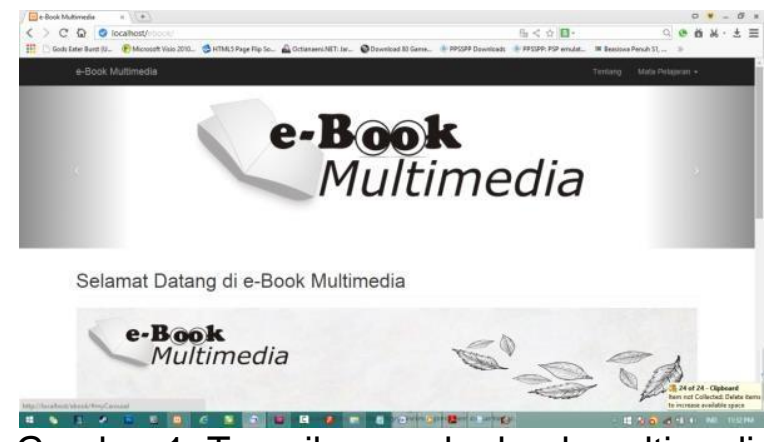

Gambar 1. Tampilan awal e-book multimedia

Berikut ini desain dari e-book animasi 2 dimensi

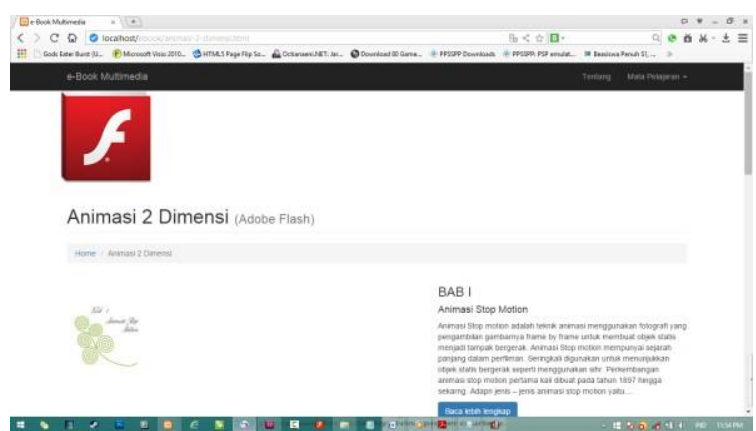

Gambar 2. Tampilan awal bab pada mata pelajaran animasi 2 dimensi 
Berikut ini desain dari buku animasi 3 dimensi

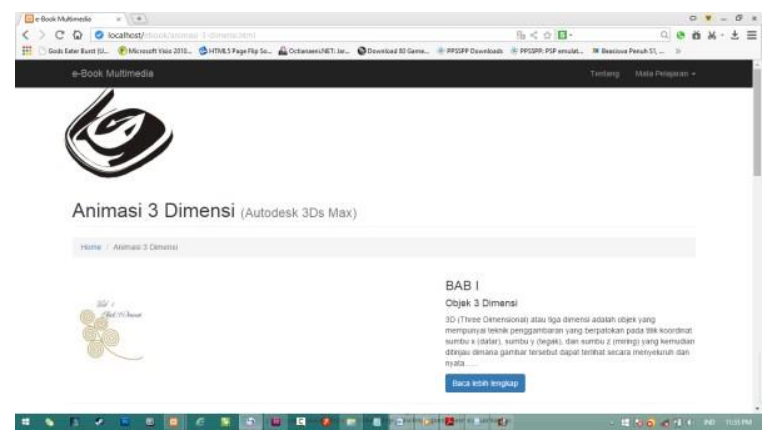

Gambar 3. Tampilan awal bab pada mata pelajaran animasi 3 dimensi

Dalam perencanaan desain e-book interaktif dibutuhkan beberapa alat dan bahan yaitu :

(1)materi Teknik Animasi 2 Dimensi dalam Buku Sekolah Elektronik

(2)materi Teknik Animasi 3 Dimensi dalam Buku Sekolah Elektronik

(3)perangkat keras berupa, laptop

(4) perangkat lunak berupa, Adobe Reader, Adobe Indesign CS5.5, Adobe Dreamweaver

CS5.5, Flipbook Maker Pro dan XAMPP

(5) gambar pendukung dari materi yang akan di bahas, dapat menggunakan CorelDraw atau

Photoshop untuk membuat serta mengedit file gambar

(6) video tutorial yang dibuat dengan camtasia

Validasi desain dilaksanakan melaui uji validasi media dan materi. Pada tahap I ini subjek sebagai responden sekaligus menjadi validator terdiri dari dua orang ahli media dan materi, yaitu dosen ahli media dan ahli isi pada bidang Pemograman Web dengan spesifikasi minimal Sarjana (S1) Program Studi Pendidikan Teknik Elektro di Universitas Pendidikan Ganesha (UNDIKSHA), dan guru pengampu mata pelajaran Jurusan Multimedia di SMK Negeri 3 Singaraja khususnya mata pelajaran animasi 3 dimensi dan animasi 2 dimensi.

\section{Hasil dan Pembahasan}

Pengembangan e-book interaktif multimedia dilaksanakan dalam dua tahap yaitu, tahap pertama dilakukannya uji validasi ahli media dan materi terhadap produk e-book interaktif multimedia, dan tahap kedua uji coba produk ke siswa Jurusan Multimedia SMK Negeri 3 Singaraja. Penelitian ini berupa penelitian dan pengembangan media pembelajaran electronic book (e-book) interaktif multimedia dalam mata pelajaran teknik animasi 3D dan teknik animasi 2D di Jurusan Multimedia SMK Negeri 3 Singaraja bertujuan untuk mengetahui kelayakan dari sebuah e-book interaktif multimedia yang dikembangkan sebagai bahan referensi atau media pembelajaran.

Pada sub penelitian tahap I ini terdiri dari empat bagian, yaitu: (1) pengumpulan data; (2) desain produk; (3) validasi desain; dan (4) revisi desain.

Berdasarkan hasil pencatatan dokumen dan hasil observasi dalam pengumpulan data pada penelitian tahap I, maka diperoleh data bahwa untuk mendukung ketercapaian pemahaman siswa terhadap media yang dikembangkan perlu dilakukan identifikasi kebutuhan untuk e-book interaktif multimedia sebagai referensi atau media pembelajaran pada Jurusan Multimedia di SMK Negeri 3 Singaraja.

Desain produk pada penelitian tahap I ini merupakan wujud dari e-book interaktif multimedia. e-book interaktif multimedia ini tersusun dari dua mata pelajaran yaitu animasi 2 dimensi dan animasi 3 dimensi. Berikut ini fungsi dari navigasi dalam e-book interaktif multimedia. 


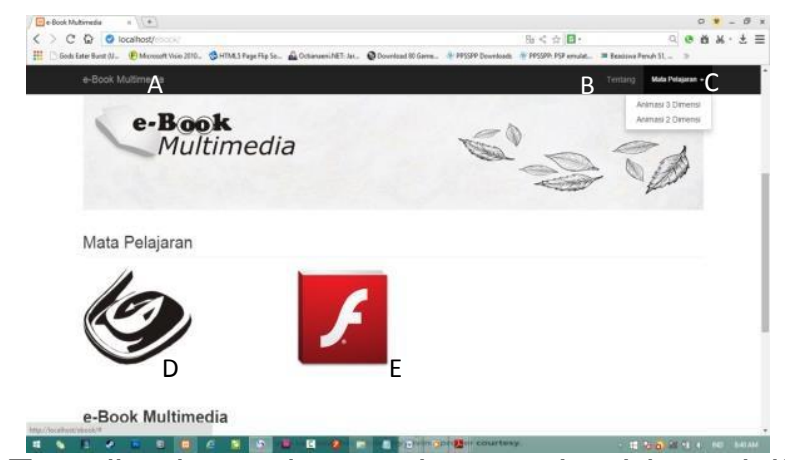

Gambar 4. Tampilan beranda atau home e-book interaktif multimedia
(A) Beranda
(B) Tentang e-book interaktif multimedia
(C) Mata Pelajaran
(D) Animasi 3 Dimensi
(E) Animasi 2 Dimensi

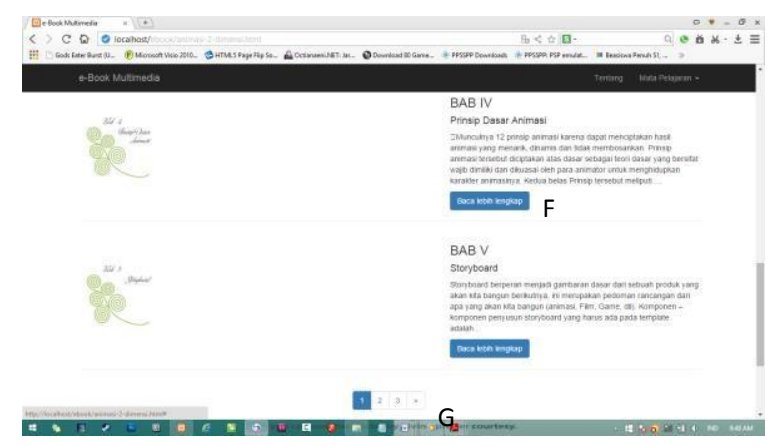

Gambar 5. Tampilan pada mata pelajaran animasi 2 dimensi

(F) Baca Lebih Lengkap, memunculkan e-book dengan tab baru

(G) Halaman

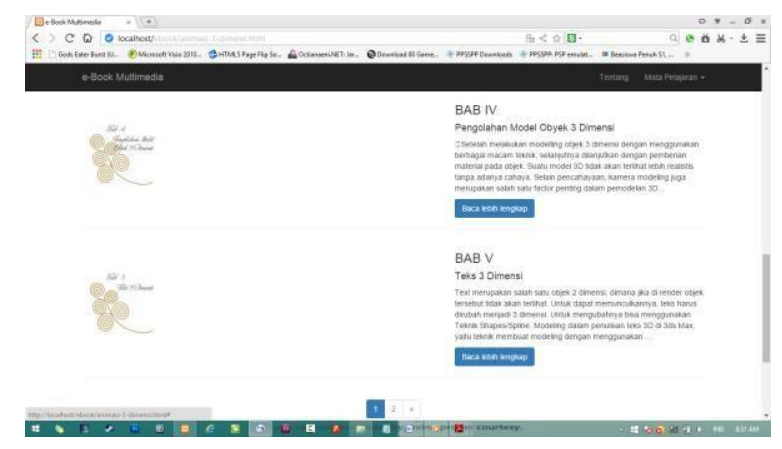

Gambar 6. Tampilan pada mata pelajaran animasi 3 dimensi 


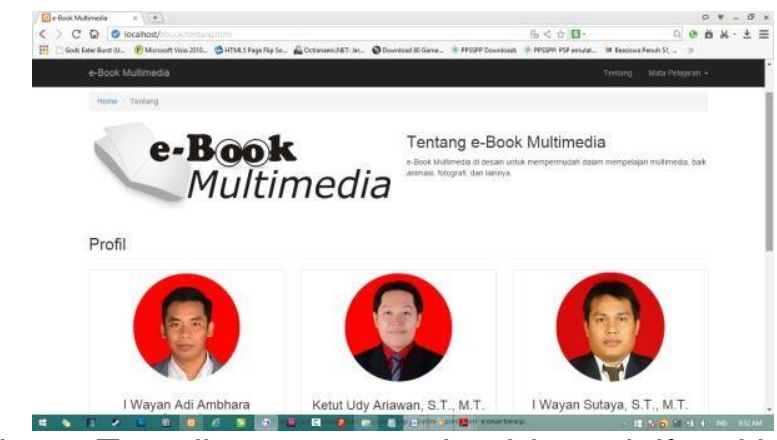

Gambar 7 Tampilan tentang e-book interaktif multimedia

Pada penelitian tahap I, pengujian terhadap tingkat kelayakan penggunaan media pembelajaran electronic book (e-book) interaktif multimedia dalam mata pelajaran teknik animasi 3D dan teknik animasi 2D di Jurusan Multimedia dilakukan dengan uji kelayakan validasi media dan materi.Data skor validasi media dan materi berupa angket diperoleh dari dosen ahli bidang pemograman web dan guru pengampu mata pelajaran animasi 3 dimensi serta animasi 2 dimensi yang dianggap telah ahli.

Hasil uji ahli pertama diserahkan kepada guru pengampu mata pelajaran animasi 3 dimensi dan animasi 2 dimensi atas nama Ibu Ni Putu Linda Ariastini, S.Pd. Berikut hasil dari validasi uji ahli. Berikut grafik tentang nilai dari hasil evaluasi ahli media pembelajaran terhadap media yang dikembangkan.

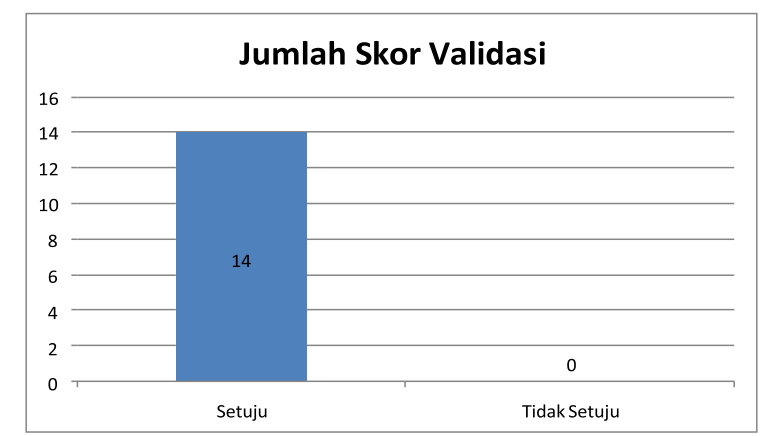

Gambar 8. Grafik jumlah skor validasi ahli media dan materi (guru)

Berdasarkan hasil penelitian dari ahli media dan materi seperti yang tercantum dalam tabel 4.1, maka dapat dihitung sebagai berikut :

$$
\begin{aligned}
& P=\frac{f}{N} \times 100 \% \\
& P=\frac{14}{14} \times 100 \% \\
& P=100 \%
\end{aligned}
$$

Setelah dikonversikan dengan tabel konversi, persentase tingkat pencapaian $100 \%$ berada pada kualifikasi layak. Adapun saran yang diberikan oleh ahli media dan materi adalah "dari segi penggunaan tolong di link atau tampilkan menu home". Hasil uji ahli kedua diserahkan kepada dosen pengampu mata kuliah pemrograman web atas nama Bapak Ketut Udy Ariawan, S.T., M.T. Berikut hasil dari validasi uji ahli. 
Berdasarkan hasil penelitian dari ahli media dan materi seperti yang tercantum dalam tabel 4.1, maka dapat dihitung sebagai berikut :

$$
\begin{aligned}
& P=\frac{f}{N} \times 100 \% \\
& P=\frac{14}{14} \times 100 \%
\end{aligned}
$$

\section{$\mathrm{P}=100 \%$}

Setelah dikonversikan dengan tabel konversi, persentase tingkat pencapaian $100 \%$ berada pada kualifikasi layak. Adapun saran yang diberikan oleh ahli media dan materi adalah "localhost diganti online". Berdasarkan penilaian dari uji validasi desain berupa media dan materi produk ini memperoleh tingkat pencapaian validasi $100 \%$ yang termasuk dalam kategori layak. Sehingga dari segi desain produk e-book interaktif multimedia ini tidak perlu direvisi.

Penelitian ini dilakukan untuk mengetahui bagaimana mengembangkan media pembelajaran electronic book (e-book) interaktif multimedia dalam mata pelajaran teknik animasi 3D dan teknik animasi 2D di Jurusan Multimedia SMK Negeri 3 Singaraja. Berikut ini perbandingan sebelum (buku sekolah elektronik) dengan sesudah (e-book interaktif multimedia) dikembangkan.

Tabel 4.3 Perbandingan Buku Sekolah Elektronik dengan E-book yang dikembangkan Buku Sekolah Elektronik E-book yang Dikembangkan

\begin{tabular}{cc}
\hline $\begin{array}{c}\text { Tampilan masih menggunakan efek } \\
\text { scroll }\end{array}$ & Tampilan menggunakan efek flip \\
\hline $\begin{array}{c}\text { Belum memuat video di dalam } \\
\text { materi }\end{array}$ & $\begin{array}{c}\text { Memuat video, baik video tutorial } \\
\text { maupun video ilustrasi }\end{array}$ \\
\hline
\end{tabular}

Validasi desain yang menggunakan instrument dengan skala Guttman untuk mendapatkan jawaban yang tegas terhadap suatu permasalahan yang ditanyakan. Instrumen ini selanjutnya diusahakan untuk mendapat menguji sejauhmana media yang dikembangkan dengan aspek penyajian isi/materi, media, desain dan penggunaan, serta bahasa dan penulisan dalam pembelajaran animasi 2 dimensi dan animasi 3 dimensi.

Hasil uji validasi dari validator dengan menggunakan angket menyatakan media pembelajaran e-book interaktif multimedia dalam mata pelajaran teknik animasi $3 \mathrm{~d}$ dan teknik animasi $2 \mathrm{~d}$ sesuai dengan konsep pada materi yang terdapat dimasing-masing mata pelajaran. 


\section{Simpulan dan Saran}

Berdasarkan hasil penelitian dan pembahasan yang telah diuraikan, dalam mengembangkan media pembelajaran electronic book (e-book) interaktif multimedia dalam mata pelajaran teknik animasi 3D dan teknik animasi 2D di Jurusan Multimedia SMK Negeri 3 Singaraja menggunakan beberapa program atau software yaitu video tutorial dibuat dengan bantuan software bernama Camtasia Studio 8 yang dikeluarkan oleh TechSmith, desain buku serta peletakan materi dibantu dengan menggunakan software Adobe Indesign, sedangkan dalam desain tampilan web dibantu dengan menggunakan software Adobe Dreamweaver, pemberikan efek berupa flip untuk setiap transisi menuju halaman berikutnya serta menyisipkan video, baik video tutorial maupun video ilustrasi menggunakan software bernama Flipbook Maker dari Kvisoft. Hasil yang diperoleh dari mengembangkan e-book interaktif multimedia terdapat perubahan penyajian dalam bentuk flip. Secara materi dilakukan dengan pendekatan nyata dalam bentuk video, baik video tutorial maupun video ilustrasi Hasil uji validasi dari validator dengan menggunakan angket menyatakan media pembelajaran e-book interaktif multimedia dalam mata pelajaran teknik animasi $3 d$ dan teknik animasi $2 \mathrm{~d}$ sesuai dengan konsep pada materi yang terdapat dimasing-masing mata pelajaran.

Berdasarkan simpulan, terdapat beberapa hal yang dapat dijadikan bahan dipertimbangkan untuk ditindaklanjuti dalam pengembangan e-book ini antara lain : (1) Penelitian ini hanya menghasilkan produk berupa electronic book (e-book) interaktif multimedia dalam mata pelajaran teknik animasi 3D dan teknik animasi 2D, maka perlu diadakan pengkajian lebih lanjut mengenai efektivitas penggunaan media pembelajaran ini (e-book) berkaitan dengan hasil belajar atau prestasi belajar. Peneliti selanjutnya dapat menggunakan media pembelajaran electronic book (e-book) interaktif multimedia dalam mata pelajaran teknik animasi 3D dan teknik animasi 2D yang telah dihasilkan untuk diteliti efektivitasnya. (2) Pengembangan media pembelajaran electronic book (e-book) interaktif multimedia ini hanya merujuk pada dua mata pelajaran yaitu teknik animasi 3D dan teknik animasi 2D di jurusan multimedia, sebaiknya dikembangkan lebih jauh pada setiap mata pelajaran pada kompetensi keahlian multimedia secara keseluruhan. (3) Untuk penelitian selanjutnya agar dilakukan penambahan kuis atau soal pengayaan guna mengetahui tingkat pemahaman siswa atau pengguna. (4) Media pembelajaran electronic book (e-book) interaktif multimedia dalam mata pelajaran teknik animasi 3D dan teknik animasi 2D telah berbasis online dengan alamat situs web http://sanuproject.com/ebook.

\section{DAFTAR PUSTAKA}

Arsyad. 2005. Media Pembelajaran. Edisi 6. Jakarta;PT Raja Grafindo Persada Ahmadi,Abu dkk. 2001. IImu Pendidikan. Edisi 2. Jakarta: PT. RINEKA CIPTA Arsyhar, Rayandra. 2012. Media Pembelajaran. Edisi 1. Jakarta:Referensi Jakarta

Jayawardana, Hepta. 2013. "Segudang Manfaat Menggunakan E-Book (Electronic Book)". Tersedia pada http://heptajayawardana.blogspot.co.id/2013/07/segudang-manfaatmenggunakan-e-book.html (diakses pada tanggal 27 September 15)

Kolordwijo. 2009. "Sekilas Info Tentang Blog". Tersedia pada https://kolordwijo.wordpress.com/2009/04/16/sekilas-info-tentang-ebook/ (diakses pada tanggal 27 September 2015)

Laila, Laila Nur. 2013. "Adobe InDesign". Tersedia pada http://adobeindesgn.blogspot.co.id/ (diakses pada tanggal 23 November 2015)

Perdana, Dian Mahendra Bromantya. 2013. "Pengembangan Buku Digital Interaktif (Budin) Berbasis Adobe Creative Suite Pada Materi Genetika di SMK". Skripsi (tidak diterbitkan). Jurusan Biologi, Fakultas Matematika Dan Ilmu Pengetahuan Alam Universitas Negeri Semarang 
Pratama, Dhimas Ardhiansyah dkk. 2013. "Pengembangan Media Pembelajaran E-Book Interaktif Pada Mata Kuliah Elektronika Digital Di Jurusan Teknik Elektro UNESA". Jurnal Pendidikan Teknik Elektro, Volume 02, Nomor 1 (hlm 331)

Syahfitri, Yunita.2011. "Teknik Film Animasi Dalam Dunia Komputer". Jurnal SAINTIKOM, volume 10, Nomor 3(hlm 215)

Santyasa, I Wayan.2007. "Landasan Konseptual Media Pembelajaran". Makalah disajikan dalam Workshop Media Pembelajaran bagi Guru-Guru SMA Negeri Banjar Angkan. Universitas Pendidikan Ganesha, Klungkung 10 Januari 2007.

Sugianto,Doni dkk. 2003. "Modul Virtual: Multimedia Flipbook Dasar Teknik Digital". Invotec, Volume 9, Nomor 2 (hlm 103-104)

Sugiyono. 2009. Metode Penelitian Kuantitatif Kualitatif dan R\&D. Bandung:Alfabeta. Sugiyono. 2015. Metode Penelitian Pendidikan. Bandung: CV ALFABETA.

Wijayanto, Muhammad Saifudin Zuhri.2014. "Pengembangan E-Modul Berbasis Flip Book Maker Dengan Model Project Based Learning Untuk Mengembangkan Kemampuan Pemecahan Masalah Matematika". Dalam Prosiding Mathematics and Sciences Forum. Universitas PGRI Semarang

Wojowasito, Soewojo dan W J S Poerwadarminta.1997. "Kamus lengkap Inggeris-IndonesiaIndonesia-Inggris Dengan Ejaan Yang Disempurnakan”. Bandung: Hasta 